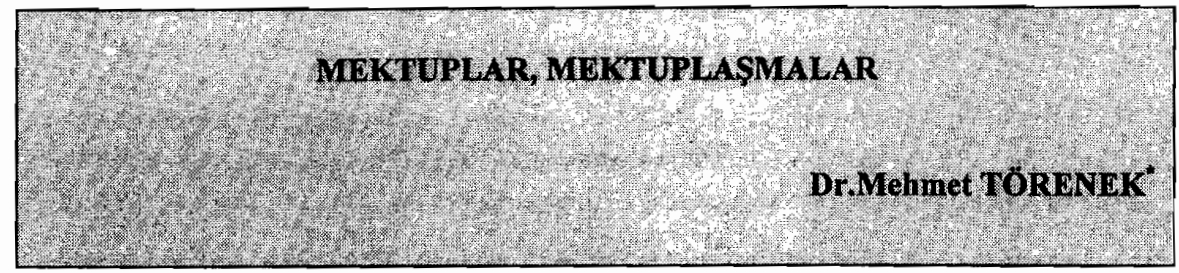

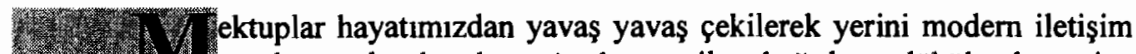
2. 1. Waraçlarına bırakmakta. Artık sevgiler kağıtlara dökülmek yerine ahizelere hapsedilmekte, fakslarla uçurulmakta, umutlar, heyecanlar kapıyı çalacak postacıya değil, telefon makinesinin manyetik alarmına endekslenmektedir. İstesek de istemesek de bu deģişim yaşanmakta, hayatın akışındaki hız ivmesi "alo" sesiyle bütünleşmektedir.

Yazının kalıcı olma yanında, dili ve üslubuyla ayrı bir boyutu vardır. Mektuplarda bu dil daha içli, daha mahrem bir ozellik kazanır. Sıcak, etkileyici, içten gelen duyguları taşıyan bir araç olur. Yıllarca bir armağan gibi saklanır, bir şiir, bir hatıra duyarlığıyla okunur. Onda şiirlere, şarkılara, manilere yer verilerek duygular kanatlandırılmaya çalışılır. Bir dosta, bir eşe, bir sevgiliye yazıldığı için de mahremdir onlar. Muhatabı tektir. Dolayısıyla böyle bir toplum ahlâkı da yerleşmiş̧ir. Mektup sadece kendisine yazılan kişiye aittir, açılmaz, okunmaz. Hatta Anadolu'da, uzaktaki bir dosttan gelen mektup yıllarca hep bir sağlık, bir varlık işareti bilinmiş, alınan mektup için ilgili şahsa sorulan "ne var" sorusuna "selam, dua" karşılığ verilerek duyguların mahremiyetine girilmemiştir.

Mektupların oznelliği daha ilk cumlede kendini belli eder. "sevgili dostum", "iki gözüm,aziz kardeşim, efendim", "muazzez efendim"lerle , yahut "muhibbim", "nur-1 aynım", "sevgilim" gibi hitap kelimelerine farkl sıfatlar eklenerek ve gőnderilen kişinin ismi yazılarak başlar. Kendinden, yaptıklarından, duş̧uncelerinden, problemlerinden, özlemlerinden, duygularından sonra selama geçilir ve mektup sona erer. Ancak genelde son cumleler de yine duygu yüklu ve özlü olur.

Son yıllarda derlenmiş mektupların yayımlanmasıyla oluşan birçok kitap çıktı piyasaya. Yıllarca eşte, dostta kalan, saklanmış mektuplar bơylece geniş okuyucu kitlesiyle buluştu. Edebiyat, sanat, yahut siyaset dunyasının, kısacası o toplumun malı olmuş kişilerin bir çok özel yơnunu tanıma firsatı yakaladı. Ancak mektupların yayımlanmasında bir ozel hayatı deşifre etme telaşı hep oldu ve olmaya devam ediyor. Gerçekten bir sanatçıdan, bir siyasetçiden, bir bilim adamından geriye kalan her șey ortaya dokiulmeli mi? Yoksa mektup mahremiyetini hep korumalı, kişiler olmůş de olsa ozel dünyalar saklı kalmaya devam etmeli mi?

\footnotetext{
* Atatürk Üniversitesi Fen-Edebiyat Fak. Türk Dili ve Edeb. Bölümu.
} 
Tanpınar'ın mektuplarını yayımlayan Zeynep Kerman, kardeşi Kenan Tanpınar'dan aldığı bazı mektupları "çok şahsi ve ailevi meselelere temas ettiği için", şairin de vasiyetine uyarak yayımlamadığını sóyler. ${ }^{1}$ Celal Nuri (illeri) de, A. Hamid'in mektupları Süleyman Nazif tarafindan yayımlandığında yazdığı bir yazıda, bazı mektupların neşrini lüzumsuz bulur ve "daire-i hususiyet ve mahremiyette cereyan eden sözler neşre gelmez." hükmünü verir. ${ }^{2}$ Abdülhak Hamid de Recaizade M Ekrem'e yazdığ bir mektubunda, mektuplaşmalarının basılması halinde bunun "hoș" olacağını, ancak çoğu yerlerin çıkarılması gerektiğini ,"çünkü çok yerleri mahremânedir, umuma arz olunmaz." sözleriyle kaygılarını dile getirir. ${ }^{3}$ Kısacası bu kaygı hep olmuş, eleştirilerde bu konu hep vurgulanmıştır.

Bunun yanında mektupların özel de olsa, kişinin kendini anlatan satırlarmda sahip olduğu ilkeleri, kararlılık yahut tereddütlerini, sevgilerini, ilgilerini, beslendiği kaynakları ögrenme imkânı buluruz. Böylece sanata, edebiyata, topluma yön vermiş kişilerin daha iyi tanınması yanında, öncülük görevlerini mektupların sıcak ikliminde sürdürmesi sağlanmış olur. Yapmak isteyip de yapamadıkları, hep hayalini kurdukları halde bir türlü gerçekleştiremediği dussünceleri , plânları yanında, kendi sıkıntılarını, açmazlarını görmek ve keşfetmek ...Çünkü onlar sanatçıyı ele veren itiraflardır, belgelerdir, ipuçlarıdır. Zeynep Kerman da Âli'ye Mektuplar'ın girişinde, hocanın kendisine yazdığı bir mektupta, eserin adını dahi vererek, mektuplarının bir kısmını yayımlamayı düşündügünu vurgulayarak, "öyle sanyorum ki Kaplan Bey, bu mektupların neşrini asıl bu noktayı açığa çıkarmak, kendisi gibi gençlere ümit ve irade aşılamak için istemiş olmalıdır." ${ }^{4}$ der ki, söylediklerimize örnek olacak birçok problemi bu mektuplarda bulmak mümkündür.

Mektuplar özel de olsa, onlarda tartışılan bir çok mesele daha sonra sanat dünyasının, düşunce dünyasının malı olmuş, mektuplar vasıtasıyla başlayan bu tartışma zamanla genişleme imkânı bulduğu gibi, karşılıklı muhatap olan kişilerin çeşitli yazılarına, yahut eserlerine ilham açısından kaynaklık etmiştir. Başlangıçta ya bir dost uyarısı, yahut da ükek ve çekingen bir şekilde ele alınan konu, karşıllıklı mektuplarla olgunlaşmış, yeni yönlendirmelerle zenginleşmiş ve bir çok sanatçı için kendi kişiliģini bulmada ilk nüve vasfı kazanmıştır. A. Hamid- N. Kemal arasındaki mektuplaşmaların, konuşulan problemler yanında, yeni adımlar için nasıl cesaretlendirici bir fonksiyon kazandığını, ne yazık ki, bizler yıllar sonra ancak farkına varabiliyoruz. Hamid'e ismiyle hitap eden ve "seni muhatap etmege adından büyuk bir kelime bulamiyorum!" diyen N. Kemal, 24.01.1882 tarihli mektubunda kendi eserlerinin "mubâhasat-1 edebiye" konusu olmasından dolayı üzüldügünü ve Hamid'in uzülmemesini ister. "Fakat zannetmem ki sen müteessir olasın, elbette

'Tanpınar' in Mektupları, (Haz. Z. Kerman), İst. 1992, s.7

${ }^{2}$ Abdülhak Hamid'in Mektupları, (Haz. İ. Enginün), İst. 1995, önsöz, s. 8'den naklen.

a.e. ,s.356

4 Kerman, Zeynep, Âli'ye Mektuplar, İst. 1992, önsöz, s.7 
olmamışsındır." der. İtiraz edenlere aldırmaması uyarısından sonra da; "Senin ne vazifen Hâmid! Sen tarih dediǧimiz umman-1 zulmetin amâk-ı hafâsına gir! Bize Eşber gibi kitaplar yaz. İskender' in ahlâkından bulyuk ahlak tasavvur ve tasvir et! Selim-i Evvelin türbesini ziyaret eyle! O ziyaretindeki hissiyâtı pâdişâh-ı azimusşşana nedim-i hâs olan Hasan Can'ın vicdânından sudûr etmiş kadar rûhâni bir belâgatle tarif et.(.....) Çalıș! Çalıș! Ben edebiyât-ı Osmaniye için tasavvur ettiğim ulviyyâtı bin türlu hissiyât ile karıştırdım; âsârımı istediğim dereceye getiremedim. Bakalım sen getirebilir misin. Getirebilirsen bir milletin mürebbiyân-1 irfânından madud olursun,"

Mektuplar, bir çok dedikoduları,̧̧ekemezlikleri, ihtirasları, basitlikleri zaman zaman konu edindiğinden, kitaplaştığında okuyucu zihnindeki bazı imajları yıkma, yok etme yönünde olumsuz bir rol de üstlenebilirler. Bir kısım yazarlar için bu kabul edemeyeceğimiz bir durum olurken, bir kısmı için bizim bakışımıza belge oluşturabilir. Özellikle bir düşünce zaviyesinden bakıyorsak bu yaklaşım daha belirgin olur. Ancak gerçek budur ve herkes nihayetinde insandır.

Mektup bizde, batı edebiyatının tesiriyle yeni bir gelişme gösterir. Deneme, makale gibi yeni bir tür değildir ama eski "münșeat zihniyeti ve bunun hazır ve sun'i kalıpları yerine (.....) muhtevayı esas alan, tabii ve sade bir mektup tarzı" yavaş yavaş yerleşmeye başlar. ${ }^{6} \mathrm{Bu}$ değişimde şüphesiz batılı sanatçıların eserleri ilk örnekler olmuş, başta N. Kemal olmak üzere, yenilił̧̣in öncüsü bir çok sanatçı, bunu bir zevk anlayışı yanında, görev bilinciyle önemsemiştir. Bizde en çok mektup yazan ve kendisinden geriye en çok mektup kalan sanatçı $\mathrm{N}$. Kemal'dir. Yıllar sonra bu mektuplar derlenerek bir araya getirilmiştir ve mektup külliyatı olarak bugün en hacimlisi ona aittir. Hatta $0,1867^{\prime}$ de yazdığı ve Tasvir-i Efkâr gazetesinde yayımladığı "Ramazan mektubu"nda "mektubu sadece muhatabının okuyacağı bir yazı olmaktan" çıkararak geniş okuyucu kitlesine sunar ki, bu yeniliğiyle "o zamana kadar edebiyatımızın mektup sahasında tanımadığı bir tarzın örneğini" vermiş olur. ${ }^{7}$ Bu genişleme, zamanla mektup türünün, bazan muhatapları belli olsa da, bir çok yeni meselenin gazete sütunlarına taşınarak konuşulmasına, yahut kụ̧̧ük kitapçıklar halinde ele alınmasına, tartışılmasına neden olmuş, ózellikle bu devrede tenkid ve tartışmanın adeta tek geçerli formu olarak bir çok eser vücuda getirilmiştir. Namık Kemal'in İran Paşa'ya Mektup (1301/1886),Tahrib-i Harabat ve Takip (1301/1885)'i bunlardandır. Ahmed Midhat Efendi de Hall'ül-Ukd (1307/1890) Ahbâr-1 Âsâra Tamîm-i Enzar (1307/1890) isimli kitaplarını "tecessüs ve zevkle okunulmasını temin gayesi ile" ${ }^{\prime 8}$ mektup tarzında yazar. Yine Muallim Naci- Beşir Fuad mektuplaşması İntikad (1887), Muallim Naci- Şeyh Vasfi mektuplaşması

5 Namık Kemal'in Mektupları, (Haz. F. A. Tansel), Ankara 1973, c.lll, s.201-204

${ }^{6}$ Akün,Ömer Faruk- Namık Kemal' in Mektupları, İst. 1972, önsöz, s.lV

7 a. e. ,s.lV-V

${ }^{8}$ Tansel, Fevziye Abdullah-Turk Edebiyatında Mektup, Tercume dergisi, c. XVI, No: $77-80$, s.400 
Şöyle Boyle (1885), Muallim Naci- A. Midhat Efendi mektuplaşması Muhaberat ve Muhaverat (1884), Beşir Fuad- Fazlı Necip mektuplaşması Mektubat(1888) isimli eserleri oluşturmuştur. Özellikle bu tanınmış edibler arasında teati edilen mektuplar bizde tenkidin yerleşmesine ve sistemleşmesine büyuk katkıda bulunmuş, sade teorik plânda değil, pratik olarak da bir çok eserin ele alınıp değerlendirilmesine, bőylece esere dönük bir dikkatin yerleşmesine neden olmuştur.

Mektup, dilinin içtenliği, sıcaklığı, duygusallıklara açık oluşu yanında, konusunun genişliğiyle de çekici gelmiş, hitap ozelliğiyle de okuyucuyu kendisine bağlamayı bilmiştir. Bütün bunlar ve daha sıralanabilecek bir çok ozellik, mektup formunun diğer edebi faaliyet alanlarında da kullanılmasına yol açmış, hemen her tlirde bu formun kullanıldığı eserler zaman zaman yayımlanmıştır. Bir kısmında ilk örnekler batıdan olsa da, tilülin ozelliği bizde de denenmesine imkân vermişstir.

Roman titrunde yer yer kullanılan farklı bir anlatım tarzı olmanın yanında, bütunüyle bu formun kullanılmasıyla yazılmış roman örnekleri batıda ve bizde mevcuttur. Lacloss'un Tehlikeli İlişkiler'i (1782), Balzac'ın Vadideki Zambak'ı (1835) bunlar arasındadır. Bizde ise Halide Edip Handan'1 (1912), Hüseyin Rahmi Mutallaka'yı (1899), Reşat Nuri Bir Kadın Düşmanı'nı (1927), Nigar Hanım Safahat-i Kalp'i (1901),Cengiz Dağc1 Anneme Mektuplar'ı (1988) bu formun ömekleriyle oluşturmuşlardır. Tabii bunlara başka ilaveler yapmak da mümkündür.

Hikâye türünde bu kullanım daha yaygındır. Bir çok yazarın hikâyelerinde mektup formunu tercih ettiğini görmekteyiz. Bütüntlyle bu tarz hikâyelerin oluşturduğ kitaplar ise fazla değildir. Mehmet Rauf'un Hanımlar Arasında (1914), Safveti Ziya'nın Hanım Mektupları (1913) ilk göze çarpan örneklerdir.

Siir turünde mektup ,daha çok isim olarak anılır. Formun şekli ozelliklerinden çok muhtevayı esas alan bir seçimdir bu. Necip Fazıl'ın Zindandan Mehmet'e Mektup, Orhan Seyfi'nin Abdälhak Hamid'e Mektup, Halit Fahri'nin Bayram Mektubu, Abdürahim Karakoç'un Hasan'a Mektuplar, Ataol Behramoğlu'nun Kızıma Mektuplar'ı mektup içtenliğine sahip birkaç şïr ơrneğidir.

Gezilip görülen yerlerle ilgili izlenimler, yahut içinde yaşanılan şehre ait gözlemler bir seyahat yazısı olarak düşünülmüsş, ancak yazıldıkları dönem içerisinde gazete ve dergilere gönderilirken mektup ismi tercih edilmiş, uzakta olan bir dostun, bir arkadaşın izlenimleri olarak parça parça yayımlanmıştır. Kitaplaşırken de aynı isim haliyle muhafaza edilmiştir. Cenap Sehabeddin'in Hac Yolunda (1909) ve Avrupa Mektupları (1919), Ahmet Rasim'in Romanya Mektupları (1916), Süleyman Nazif in Elcezire Mektupları (1906) Haldun Taner'in Berlin Mektupları (1984), Ayşe Göktürk Tunceroğlu'nun Amerika Mektupları (1992) bunların bir kısmıdır. Ahmet Rasim ile Mustafa Kutlu'nun aynı adı taşıyan Sehir Mektupları (1912//1995) ise izlenimlerin bir sohbet havası içinde sunulduğu eserlerdendir.

Mektup formu bazı yazarlarımız tarafindan da fikra, sohbet ve deneme türündeki yazılarında kullanılmıştır. Nurullah Ataç'ın Okuruma Mektuplar'ı (1958) 
ile kitaplaşmamış olan Keziban'a Mektupları, Haldun Taner'in Devekuşuna Mektupları (1960), Abdürrahim Karakoç'un Çobandan Mektuplar'1 (1997) gibi..

Tasavvuf ve tarikat onderlerinin müitlerine hitaben yazókları, yahut uzaktaki bir bağlısına gőnderdikleri mektuplar da zaman içerisinde derlenmiş ve bağlılarının adeta el kitabı olarak okunmuş, yaygınlaşmıştır. İmam Rabbani'nin, Mevlana'nın, Elhac Muhammed Esad Efendi'nin Mektubat'ları, Seyh Hasan Sezai Efendi'nin Mektubat-1 Hazreti Sezai'si bunlardan bazısıdur.

\section{MEKTUPLAR BİBLIYYOGRAFYASI}

Abdulhak Hamid'in Mektupları (Haz. Inci Enginün), İstanbul, Dergâh yay. 1995, 2 cilt, 464-846 s. (llk baskısı Mektuplar adıyla, bak)

Alamanya Gurbeti- Sabri'ye Mektuplar- Fethi Savaşçı, İst. Yeditepe yay. 1977, 112 s.

Ali İlmi Fani'ye Bir Mektup "Şiir ve Sanat Anlayışı Üzerine", (Haz. Abdullah Uçman), İst. Kitabevi 1996, $112 \mathrm{~s}$.

Âli'ye Mektuplar-Mehmet Kaplan (Haz. Zeynep Kerman), İst. Dergâh yay. 1992, $271 \mathrm{~s}$.

Ankara, Güneș mat. 1949, 168+4 s.

Arkadaşım Orhan Kemal ve Mektupları, (Haz. Fikret Otyam), İst. E yay. 1975, 496 s.

Atatïrk'ün Özel Mektupları (Haz. Sadi Borak), İst. Varlık yay. 1961 (42 mektup), 84 s. /1970 (80 mektup), 190 s./ 1998 (157 mektup), 316 s.

Atsız'dan Adile Ayda'ya Mektuplar, (Haz. Fethi Tevetoglu), Ankara, Ayyıldız mat. $1988,126 \mathrm{~s}$.

Aziz Nesin Ali Nesin Mektuplaşmaları, İst. Düşün yay. 4 cilt, 1994-95, $334+252+238+312 \mathrm{~s}$.

Aziz Nesin Tahsin Saraç Mektuplaşmaları, İst. Düşün yay.1994.

Baba İnönü'den Erdal İnönü'ye Mektuplar, (Haz. Sevgi Özel), Ankara, Bilgi yay $1988,234 \mathrm{~s}$.

Başvekil Sayın Adnan Menderes'e Devletimiz Hukuku Hakkında Mektuplar- Erhan Löker, Ankara, Örnek mat. 1955, 52 s. 
Bedrettin Tuncel'e Mektuplar, (Haz. Alpay Kabacalı), İst. Yapı Kredi yay. 1995, $125 \mathrm{~s}$.

Beşir Fuad'ın Mektupları "İlk Türk Materyalisti", Haz. C. Parkan Özturan), İst. Arba yay. [t.yok], $80 \mathrm{~s}$.

Beyaz Mektuplar- Bekir Berk, (Haz.Ahmet Ersöz), İst. Feza yay. 1993, 299 s.

Bilinmeyen Mektuplarıyla Nazım Hikmet Orhan Kemal Dostluğu- Kemal Sülker, İst. Amaç yayıncılık, 1988, 141+17 s. (1988/1990/1991)

Bir Dostun Mektupları- Mahmut Goloğlu, Ankara, Kalite mat. 1974, 103 s.

Bir Kürt Aydınından İsmet İnönü'ye Mektup- Mustafa Remzi Bucak, İst. Doz yay. $1991,116 \mathrm{~s}$.

Bir Kürt Aydınından Mustafa Kemal'e Mektup- Celadet Bey, (Haz. Emir Celadet Ali Bedirxan), İst. Doz yay. 1992, $120 \mathrm{~s}$.

Bir 150'ligin Mektupları- Ali İlmi Fani,"Ali İlmi Fani'den Rıza Tevfik'e Mektuplar", (Haz. Doç. Dr. A. Uçman- Dr. H. İnci), İst. Kitabevi 1998, $208 \mathrm{~s}$.

Bitmeyen Hasret- Berrin Menderes, (Haz.Nazlı Ilıcak), İst. Dem yay.1989, 219 s. (3.b.)

Bursa Cezaevinden Va-Nu'lara Mektuplar- Nazım Hikmet, İst. Cem yay. 1970

Cemal Süreya'dan Mektuplar, (haz. Ahmet Arif), İst. Kaynak yay. 1992, 96 s.

Cevdet Kudret'e Mektuplar, (Haz. İ. Kudret- H. İnci), Ankara Ümit yay. 1995, 279 s.

Cornelius'a Mektuplar- Orhan Peker, (Haz. Ferit Edgü), İst. Yapı Kredi yay. 1993, $182 \mathrm{~s}$.

Çilehane Mektupları- Tahir Olgun, (Haz. C. Kurnaz- G. Erişen), Ankara Akçağ yay. $1995,259 \mathrm{~s}$.

Din Üzerine Paşama Mektuplar-Ayşe Nil, İst. Sarmal yay. [1997], $160 \mathrm{~s}$.

Dost Mektuplar- Yusuf Ziya İnan, İst. Sorgut yay. 1978, $272 \mathrm{s.}$

Dost Mektupları "Mektuplarıyla Edebiyatçılarımız", (Haz. Y. Nabi Nayır), İst. Varlık yay. 1972, $196 \mathrm{~s}$.

Döne'ye Mektuplar- Ali Kemal Gözükara, [y. y. yok], 1992, 141 s.

Edebi Mektuplar "Divan Edebiyatının Bazı Beyitlerinin Izahına Dair" -Tahir Olgun, (Haz. Cemal Kurnaz), Ankara, Akçağ yay. 1995210 s. 
Edebiyatçı Jön Türklerin Mektupları "Jön Türklere dair Vesikalar 1",(Haz. Doç. Dr. Birol Emil), İst. İstanbul Üniv. Edebiyat Fak. Yayını 1982, $116 \mathrm{~s}$.

Edebiyat-ı Cedide'ye Dair Ali Ekrem'den Rıza Tevfik'e Bir Mektup, (Haz. Doç. Dr. Abdullah Uçman), İst. Kitabevi 1997, 136 s.

Enver Paşa'nın Özel Mektupları, (Haz.Arı İnan), İst. İmge kitabevi, 1997, 578+6 s.

Ermeni Rahiple Mektuplaşmalar- Yalçın Küçük, İst. Tekin yay. 1989, 88 s.

Ertugrul Süvarisi Ali Bey'den Ayşe Hanım'a Mektuplar (Haz.Canan Eronat), İst. Yapı Kredi yay. 1995, $84 \mathrm{~s}$.

Evime ve Nihal'e Mektuplar- C.Sıtkı Tarancı, (Haz. Prof Dr. İnci Enginün), Ankara TDK yay. $1989,96+8 \mathrm{~s}$.

Fuzuli'nin MektupIarı, (Haz. A.Karahan), İst. Horoz basımevi, (İst. Üniv. Edebiyat Fak. Türk

Dili ve Edeb. Dalı Mezunları Cemiyeti yayıni:No:4)

Geceyarısı Mektupları-Salah Birsel, İst. Bağlam yay. 1991, $120 \mathrm{~s}$.

Genç Bir Şairden Genç Bir Şaire Mektuplar-A. Behramoğlu- İ. Özel, Ankara, Oglak yay. $1995,236 \mathrm{~s}$.

Gönderilmeyen Mektuplar- Suat Taşer, İst. Yeditepe yay. 1969, $128 \mathrm{~s}$.

Görülmüştür- Hapishaneden Mektuplar- (y.yok), Ankara, Yarın yay. 1985, $110 \mathrm{~s}$. (1986)

Gülşen-i Mektubat- Mehmed Necib (Midillili), İst. Kasbar mat. 1308/1891, 217 s.

Hanım Mektupları- Halide Nusret (Zorlutuna), İst. Orhaniye mat. 1923, 79 s.

Hususi Mektuplarına Göre Namık Kemal ve Abdülhak Hamid, (Haz. F. Abdullah Tansel),

Ankara, Güneș mat. 1949, $172 \mathrm{~s}$.

Hüseyin Rahmi Gürpınar'ın Mektupları ve Tiyatro Eleştirileri, (Haz.AbdullahGülçin

Tanrıkulu), İst. Özgür yay. 1998, $295 \mathrm{~s}$.

Hüsnü Akıncı'dan Tansu Çiller'e Mektuplar, Ankara, Bilkamat yay. 1997, 309 s.

İki Gözüm,Aziz Kardeșim,Efendim, (Haz.Nüket Esen), İst. Yapı Kredi yay. 1994, $143 \mathrm{~s}$.

Ingiltere Mektupları- Hasan Ali Yücel, Ankara, Türk Tarih Kurumu basımevi, 1958, 160 s. (İş Bankası Külturr Cep kitapları:No:8) 
İnkılap Mektupları- Uğur Mumcu, Ankara, Uğur Mumcu Araştırma Vakfi yay. 1987, 238 s. (16. B.1997)

İntikad- M. Naci- Beşir Fuad, İst. Mahmutbey mat. 1304/1887, $101 \mathrm{~s}$.

Kardeş Mektupları- B. Rahmi Eyüboglu, (Haz. M. Hamdi Eyüboglu), Ankara, Bilgi yay. $1985,362 \mathrm{~s}$.

Kemal Tahir'den Fatma İrfan'a Mektuplar, İst. Sander yay. 1979, $383 \mathrm{s.}$

Kemal Tahir'e Mahpushaneden Mektuplar- Nazım Hikmet, Ankara, Bilgi yay. 1968, 417 s. (1975/1990/1991/1992/1996)

Kendi Mektuplarıyla Enver Paşa, (Haz. Şükru Hanioğlu), İst. Der yay. 1989, $286 \mathrm{~s}$.

Limni ve Malta Mektupları-"Ziya Gökalp Külliyatı 11", (Haz. F. Abdullah Tansel), Ankara, Türk Tarih Kurumu basımevi 1965, XX+624 s. (Türk Tarih Kurumu yay. No:18)

Lüsiyen Hanım'dan Abdülhak Hamid'e Aşk Mektupları (Çev. İsmail Yerguz), Ankara Oglak yay. 1997, 203 s. (Eserin 1. Baskısı Fransızca yayımlanmıştır: Lettres a Abdülhak Hamid 1920-1927- Lüsiyen Abdulhak Hamid, İst. Matbaacılık ve Neşriyat Türk An. şti. 1932, 192 s.)

Mach l'den Mektuplar- Sevim Burak, İst. Logos yay. 1990, $270 \mathrm{~s}$.

Mamak Mektupları- Yılma Durak, Ankara, Ocak yay. 1987,96 s.

Mektubat- Beşir Fuad- Fazlı Necip, İst. Mihran mat. 1305/1888, 127 s. (1313)

Mektuplar- Abdülhak Hamid, (Yay. Süleyman Nazif), İst. Matbaa-i Âmire, 1334/1918, cilt, $331+338 \mathrm{~s}$

Mektuplar- Ahmet Hamdi Tanpınar, (Haz. Zeynep Kerman), Ankara, Kültür Bak. yay. 1974, Vll+328 s. (2.b. Tanpınar'ın Mektupları ismiyle, İst. Dergâh yay. 1992,275 s.)

Mektuplar- Behçet Necatigil, (Haz. Ali Tanyeri-Hilmi Yavuz), İst. 1000 Tane yay. 1989

Mektuplar- M. Nusret Tura, (Haz. M. E. Kılıç), İst. İnsan yay. 1995, 208 s.

Mektuplardan Gelen Ses- Samiha Ayverdi, İst. Kubbealtı Neşriyat, 1983, 103 s.

Mektuplarım- M. Naci, İst. Matbaa-i Ebüzziya, 1303/1886, 288 s.

Mektuplarım, Konuşmalarım- Dr. Zeki Başar, Ankara, Gürsoy basımevi 1970, 396 s. (s.7-170 arasinda muhtelif mektuplar)

Mektuplarıyla Halikarnas Balıkçısı, (Haz. Azra Erhat), İst. Çağdaş yay. 1976, $296 \mathrm{s.}$ (1979/1980/1985) 
Mevlana'nın Mektupları, (Haz. M. F. Nafiz Uzluk), İst. Sebat basımevi 1937, $174+27 \mathrm{~s}$.

Muhaberat ve Muhaverat- A. Midhat-M. Naci, İst. Tercüman-1 Hakikat mat.1301/1884, $208 \mathrm{~s}$.

Namık Kemal' in Mektupları- Ömer Faruk Aklin, Ist. Edebiyat Fak. Mat. 1972, 544 s. (F.A.Tansel tarafından hazırlanan mektupların kronolojik bir tetkiki ve tenkidi)

Namık Kemal'in Mektupları, (Haz. F. Abdullah Tansel), 4 cilt, Ankara, Türk Tarih Kurumu basımevi, I. İstanbul, Avrupa ve Magosa Mektupları, 1967, XLlll+518 s.

Il. İstanbul ve Midilli Mektupları 1, 1969, XXX+532 s.

11l. Midilli Mektupları 11,1973, LXXI+527 s.

IV. Rodos ve Sakız Mektupları, 1986, LXX1ll+760 s.

Nazım ile Piraye, (Derl. Memet Fuat), İst. De yay. 1975, 319 s. (mektuplar-şiirler),

$(1976 / 1988 / 1990 / 1991 / 1995)$

Nazım' in Bilinmeyen Mektupları (Adalet Cimcoz'a Mektuplar 1945-1950), (Haz. Sukran Kurdakul), Ist. 1986, Broy yay. 110 s. (1986/1987)

Notlar / Mektuplar-Kemal Tahir, İst. Baglam yay.1993, 342 s.

Oglum, Canım, Evladım, Memedim (Cezaevinden Memet Fuat'a Mektuplar)- Nazım Hikmet, İst. De yay. 1968, 173+8 s. (Sonraki baskılar, Cezaevinden Memet... ismiyle 1994)

Onụç Günùn Mektuplarn- Cemal Süreya, İst. Can yay. 1990, 107 s. (1992/1998)

Osmaniyeli Mektuplar- O. Nuri Poyrazoğlu, İst. Ürün yay. 1998, $119 \mathrm{~s}$.

Ögrencime Mektuplar-Vehbi Vakkasoğlu, İst. Nesil Basım yayım. 1996-97, 3.c. $202+208$ +248 s.

Paris'ten Bir Mektup- Mustafa Fazıl Paşa, İst. Artin Asaduryan mat. 1326/1910, 28 s.

Piraye'ye Mektuplar- Nazum Hikmet, (Haz. Memet Fuat), İst. Adam yay. 1998, 2 cilt, $367+372 \mathrm{~s}$.

Stalingrad'dan Son Mektuplar- Muammer Sığırcı, Ist. Kıyı yay. 1988, 45 s. 
Şiirin Kanadında Mektuplaşmalar, A. Behramoğlu- M. Demirtaş, İst. Toplumsal Döntişüm yay. 1997.

Söyle Böyle- Muallim Naci- Şeyh Vasfi, İst. Matbaa-i A.K. Tozllyan, 1302/1885, $109 \mathrm{~s}$.

Tanpınar'dan Hasan Ali Yücel'e Mektuplar, (Haz. C. Yücel Eronat), İst. Yapı Kredi yay. $1998,102 \mathrm{~s}$.

Temel Ağa'nın Mektupları, (Yukksek sesle okuyan: M. Reşat Sümerkan), İst. Anadolu Sanat yay. 1997, $98 \mathrm{~s}$.

Tezer Özlü'den Leyla Erbil'e Mektuplar, (Haz. Leyla Erbil), İst. Yapı Kredi yay. 1995, 65 s. (2.b. 1996)

Turan Dursun'a Mektuplar- İlhan Arsel, İst. Kaynak yay. 996, $143 \mathrm{~s}$.

Ünlülere Mektuplar-T uran Dursun, İst. Kaynak yay. 1993, $80 \mathrm{~s}$.

Yakup Kadri'den Hasan Ali Yücel'e Mektuplar, (Haz. C. Yücel Eronat), İst. Yapı Kredi yay. 1996, $63 \mathrm{~s}$.

Yaşanmamış Mektuplar- Turhan Oguzbaş, İst. Ay yayınevi 1965, $60 \mathrm{~s}$.

Yeter ki Kararmasın- Onat Kutlar, İst. De yayınevi 1984, 85 s. (Cezaevindeki gençlere yazılmıs mektuplar)

Zincirbozan Mektupları- S. Demirel- N. Ilıcak, (Haz. Nazlı Ilıcak), İst. Dem yay. 1990, 254. s. (5.b.)

Ziya'ya Mektuplar- C. Sitkı Tarancı, (Haz. Ziya Osman Saba), İst. Ekim basımevi 1957,203 s. (1-39 s. Cahit'le Gunlerimiz- Z. O. Saba)

\section{ANTOLOJILER}

Dünya Yazınından Seçilmiş Mektuplar (Haz. İnci Asena), İst. Adam yay. 1994, 231 $s$.

Edebi Aşk Mektupları, İst. Bolayır yayınevi, 1967, 224 s.

En Güzel Aşk Mektupları-Enver Doyuran, İst. Güryay mat. 1974, 96 s.

Gençlere Aşk Mektup Örnekleri- Nihat Özcan, İst. Eskin mat. 1977, 160 s.

Güzel Yazılar: Mektuplar, (Haz. I. Parlatır- İ. Enginün- O. Okay, Z. Kerman- K. Yetiş-N. Birinci), Ankara, TDK yay. $242 \mathrm{~s}$. 
Mektup Seçkisi, (Haz. Gürsel Aytaç), Ankara, Gündoğan yay. 1992, 198 s.

Sevgiliye Mektuplar ve Gençlere Aşk Ögütleri, İst. Bolayır yay. 1965, 160 s.

\section{ÖZEL SAYILAR}

Düş Çınarı, No:9, Mart-Nisan 1998

Tercüme, C.XVI, No:77-80, 1964

Ttirk Dili, No:274, Temmuz 1974 